IAU Commission 26

Double and Multiple Stars

Business meeting: August 19, 1994, 14:00-15:30

1. Greetings and Introductions. President Helmut A. Abt presided; about 35 attended. The names of the preceding officers are Helmut A. Abt, Pres.; Charles E. Worley, Vice-Pres.; Harold A. McAlister, Past-Pres.; Organizing Comm.: P. L. Bernacca, H. A. McAlister, and E. I. van Dessel (all retiring); Y. Y. Balega, F. C. Fekel, C. D. Scarfe, and H. Zinnecker (all continuing). The new officers elected by mail are Charles E. Worley, Pres.; Hans Zinnecker, Vice-Pres.; Helmut A. Abt, Past-Pres.; Organizing Comm.: C. Allen, W. I. Hartkopf, and $\mathrm{A}$. A. Tokovinin plus the above continuing members.

2. Necrology. The following members and valued friends died since the last General Assembly:
Sylvain Arend
Antoine Duquennoy
Robert $P$. Harrington
Mario G. Fracastoro
Ingemar Furenlid
Wilhelm Gliese
Erank Holden
Goro Ishida
Zdenek I. Kopal
Niels $P$. Wieth-Knudsen

3. Co-option of New Members. The following have been added as new members of the commission:

$\begin{array}{ll}\text { Joannia Anodova } & \text { (Russia/Japan) } \\ \text { Robert } w . \text { Argyle } & \text { (England) } \\ \text { Miguel-Angel Herrera } & \text { (Mexico) } \\ \text { Robert Hindsley } & \text { (USA) }\end{array}$

4. Future Meetings:

June 1995, Calgary, Canada: "Binaries in Clusters" This was approved by the commission in a mail election but not approved as an IAU Colloguium. It will be held under other sponsorship. Eugene Milone described the meeting plans.

September 1996, Santiago de Compostela, Spain:

"Binary Stars: Two Centuries Later". It is not clear whether the University of Santiago de Compostela will be able to host this meeting. Christine Allen (Mexico) will work with Drs. Docobo and Ling to formulate plans. September 1996, Grenoble, France: "Herbig-Haro Flows and the Birth of Low-Mass Stars". The commission 
members did not feel that there was much overlap between this topic and visual double stars. Also the commission hesitated to sponser two international meetings in the same month, so it declined to sponsor this meeting.

5. Information Circular. This circular was started in 1954 by Paul Muiller. It is sent to about 50 libraries and 100 commission members. The printing and distribution costs are not a burden to the new editors, Drs. J. A. Docobo and J. F. Ling. We we are indebted to our new editors. We also heartily thank Dr. Paul Couteau for having edited and distributed the circulars from 1983 to 1993 (Nos. 91-120). The new editors would like to expand its contents, so astronomers are encouraged to send to them information about new papers concerning double stars. Dr. Hartkopf is willing to distribute the future circulars on WWW.

6. Specific Topics. a. Hartkopf announced that a Third Speckle Catalog will be distributed by CHARA in 1995; the previous two were published in 1984 and 1988. Known errors in published information should be sent to him. It will include cross-references and will be distributed also on WWW.

b. A resolution proposed by $Y$. Kondo to protect the Julian Date definition was passed by the commission. It urgued that we not use the "Modified Julian Dates" that delete 2,400,000.5. The confusion is in the subtraction of 0.5 day.

c. Observing time of large telescopes for double-star research. Dr. Ling proposed that we advocate that more such time be allotted, but the commission felt that outside pressures on telescope allocation committees might be counterproductive.

d. Pres. Abt described the current and evolving plans for restructuring the IAU. Those would not endanger the continued existance of the existing commissions. 


\title{
COMMISSION NO. 27: VARIABLE STARS (ETOILES VARIABLES)
}

\section{Report of Meetings: August 19 and 24, 1994}

PRESIDENT: John R. Percy

SECRETARY: Luis A. Balona

\section{THE ORGANIZING COMMITTEE}

President: M. Jerzykiewicz (Poland)

Vice-President: D. Kurtz (South Africa)

Election of the following committee members (in addition to ex-officio members) was approved:

\author{
L.A. Balona (South Africa) \\ T.G. Barnes (USA) \\ C.J. Butler (UK) \\ J. Christensen-Dalsgaard (Denmark) \\ J.A. Mattei (USA) \\ M. Rodono (Italy) \\ J. Shi-Yang (China) \\ M.A. Smith (USA) \\ M. Takeuti (Japan)
}

The rule that committee members serve a maximum of two consecutive terms was approved. New members could be added between GA's, if necessary.

\section{SUPPORT OF WORKING GROUPS}

Commission 27 will support the WGs on Active B Stars, Ap and Related Stars, and Peculiar Red Giants.

\section{RESOLUTIONS}

The resolution to abandon the use of Modified Julian Day (MJD), proposed by Commission 42, was unanimously endorsed by Commission 27 . The Commission also gave support to the recommendation that Epoch 2000 coordinates be used for Novas and Supernovas.

\section{REPORT ON GCVS}

N.N. Samus reported on the current and future status of the General Catalogue of Variable Stars (GCVS). The 4 th edition is now complete. The 5 th edition will include variables in external galaxies. Positional information in the new edition will be improved. IAU funding will cease at the end of 1994, but there is enough money to finish the 4th edition.

There was much discussion concerning the vastly increasing numbers of new variables which are being detected by current surveys. It is not clear how these new stars are to be integrated in future editions of GCVS. It is essential that new editions should be available as a CD-ROM.

The Committee unanimously supported a motion of appreciation and support for the continued publication of GCVS. 


\section{REPORT ON IBVS}

K. Olah reported on the Information Bulletin on Variable Stars (IBVS). The current editorial board consists of Balona, Breger, de Groot, Hall, Kondo, Percy, Rodono, Samus, Smak, Sterken (Chair) and Le Contel. Since the inception of refereeing, the number of manuscripts has stabilized at about 150-160 per year.

One of the major changes to be made is that papers can in future be submitted and retrieved electronically. Experiments show that the best format is compressed PostScript files. A World-Wide Web (WWW) home page is also available. It is expected that private subscribers will make use of this facility to retrieve copies of the IBVS, but paper versions will still be mailed to subscribing libraries, and others without access to e-mail.

\section{REPORT ON VISUAL OBSERVATIONS OF VARIABLE STARS}

J. Mattei reported on the need for standardizing the format of finding charts. There is a lack of photometric sequences. The use of the Hubble Telescope Guide Star Catalogue is unsatisfactory for this purpose. A standardized format for electronic reporting is required. The importance of quality control was stressed, but this has to be balanced against the rapid availability of data. One possible solution is to flag those observations which have not been controlled. The possibility of establishing a single electronic data base, probably on the WWW, needs to be considered.

The need for stronger ties between professionals and amateurs was stressed. More meetings, such as the recent one in Brussels, will help in this regard.

\section{RESTRUCTURING OF COMMISSIONS}

J. Percy reported on the proposal for restructuring commissions. Commissions will continue to exist in their present form, but Commissions 27 and 42 will form a new structure called a "Division" which will have its own President and on which the two Presidents and Vice-Presidents of Commissions 27 and 42 will serve. The task of a division will be, among other things, to endorse symposia and colloquia. It is not clear at present how the new structure will work - matters will be clearer by the time of the next GA.

\section{FUTURE MEETINGS}

The following meetings have been or will be sponsored or supported by Commission 27: Workshop on Time Series Analysis, Optical and IR interferometers, Stellar Surface Structure (Symposium 176), Astrophysical Applications of Stellar Pulsation (Colloquium 155), Workshop on CV's.

Possible meetings on Carbon Stars, HD Stars, AGB Stars, Ap Stars and Binary Stars have been proposed and may require the attention of the Commission.

\section{BULLETIN BOARD}

M. Jerzykiewicz suggested that an electronic bulletin board be established for Commission 27.

\section{ARCHIVES}

The archive of unpublished photoelectric observations continues to be maintained by E.G. Schmidt. 
COMMISSION NO. 28

GALAXIES

President: Ed Ye. Khachikian

Vice President: Virginia Trimble

Activities During the 22nd General Assembly

Scientific: The Commission sponsored Symposium 164 (Stellar Populations) and Joint Discussion 5 (Activity in the Central Parts of Galaxies), and co-sponsored Symposia 167, 168, and 169 and Joint Discussion 1 . Proceedings of the symposia will appear in separate volumes and papers from the joint discussion will appear in the 1995 volume of Highlights of Astronomy.

Organizational: The Commission members participating in the business session on 18 August agreed to join, on an experimental basis, with Commission 27, Cosmo1ogy, in a group on Galaxies and the Universe. Some preliminary thoughts on making use of this new structure included the possibility of a Joint Working Group on large scale structure and eventual division into three Commissions on Normal Galaxies and Clusters; Active Galaxies; and Cosmology.

Officers and Committee: The following were elected during the business meeting. President, Virginia Trimble (USA), Vice-President, Francisco Bertola (Italy), Continuing Members of the Comittee, Marie-Helene Ulrich (Germany), Gustavo Bruzual (Venezuela), Frank Israel (Netherlands), Jian-Shen Chen (China), and Ed Khachikian (Armenia, immediate past president). New Members of the Committee Michael Feast (South Africa), John Huchra (USA), Sandip Chakrabarti (India), Richard Wielebinski (Germany), and Alexander Zasov (Russia). The members retiring from the Committee, with the thanks of the Commission, were Richard Ellis (UK), Ken Freeman (Australia), John Gallagher (USA), Sadanori Okamura (Japan), and Gustav Tammann (Switzerland, past president).

Working Groups: The active working groups are Redshifts (chair, John Huchra) and Photometry and Internal Kinematics (chair, Ronald Buta). Thw WG on Space Schidts (chair, Halton C. Arp) asked to move to another Commission as part of the WG on Wide Field Imaging. The Magellanic Clouds WG (past chair, Nolan Walborn) requested to be disbanded; and the Supernova WG (past chairs, William Liller and Virginia Trimble) feels that it is no longer necessary and should also be regarded as disbanded.

Commission Membership: Fourteen people, who had indicated to the President during the triennium that they would like to become part of Commission 28, were elected to membership, in a few cases subject to their being elected to the IAU during the General Assembly. Owing to the very short interval between opening and closing assemblies, no complete list was available of incoming Union members who had requested membership in Commission 28 , but we believe that there are at least several dozen of these. 